\title{
Confluências da expansão da educação superior brasileira no período de 2000 a 2012 e o processo de Bolonha
}

\author{
Altair Alberto Fávero* \\ Carina Tonieto $^{* *}$
}

\section{Resumo}

O presente artigo trata da possível relação entre a expansão da Educação Superior Brasileira e o Processo de Bolonha. Nosso objetivo, nos limites de um breve ensaio, é analisar que confluências existem entre as políticas públicas expansionistas da Educação Superior ocorridas recentemente no Brasil e os princípios expressos na Declaração de Bolonha. Para tanto, iniciamos apresentando os números da expansão da Educação Superior no Brasil no recorte temporal 2000-2012; na sequência, tratamos dos princípios do processo de Bolonha como sendo a resposta europeia aos desafios locais e globais da expansão e contestação do modelo tradicional de educação superior vigente na década de 1990; por fim, analisamos, a partir de algumas evidências, que relações existem entre o processo de Bolonha e a expansão da Educação Superior no Brasil ocorrida no início do século XXI.

Palavras-chaves: Expansão da Educação Superior. Políticas Educacionais. Processo de Bolonha.

Se há nove séculos atrás Bolonha concebeu a instituição que se espalhou primeiramente pelo ocidente e depois pelo mundo todo, no apagar das luzes do século XX, Bolonha inaugura um processo que pode vir a transformar consideravelmente a universidade na Europa e, talvez, em outras partes do mundo, como a América Latina

(DIAS SOBRINHO, 2009, p. 131).

Recebido: 13/05/2015 - Aprovado: 27/08/2015

http://dx.doi.org/10.5335/rep.v22i2.5577

Pós-Doutorado (Bolsista Capes) pela Universidad Autónoma del Estado de México (UAEMéx), Doutorado em Educação (Ufrgs), Mestre em Filosofia do Conhecimento (PUCRS), Especialista em Epistemologia das Ciências Sociais (UPF) e Graduado em Filosofia (UPF). Atua como professor e pesquisador no Curso de Filosofia, no Mestrado e Doutorado em Educação da Universidade de Passo Fundo/RS/Brasil. E-mail: altairfavero@gmail.com

** Doutoranda em Educação (Universidade de Passo Fundo/UPF/RS/Brasil), Mestre em Educação (UPF/Bolsista Capes), especialista em Gestão Educacional (UFSM), graduada em Filosofia (UPF). Atua como professora no curso de Filosofia e na área de Ética e Conhecimento da Universidade de Passo Fundo/RS/Brasil. E-mail: tonieto.carina@gmail.com 


\section{Considerações iniciais}

Mais de quinze anos distancia nosso tempo presente e a Declaração de Bolonha, firmada por 29 ministros de educação da Europa, em 19 de junho de 1999. Um documento curto, de quatro páginas, representa a articulação de ideias, políticas e compromissos que constituem os indicativos de um importante processo de reforma da educação superior em andamento na Europa. Em seu primeiro parágrafo, declara a "conscientização crescente", tanto do mundo político e acadêmico quanto da opinião pública "da necessidade de criar uma Europa mais completa e alargada, nomeadamente, considerando e dando solidez à sua dimensão intelectual, cultural, social, científica e tecnológica". A ideia de "Europa do Conhecimento" é indicada como sendo "um fator imprescindível ao crescimento social e humano, um elemento indispensável à consolidação e enriquecimento da cidadania Europeia".

Os objetivos da Declaração são sintetizados por Dias Sobrinho (2009, p. 133) da seguinte maneira: "pôr em prática um sistema de titulações compatível e comparável, que também permita a expedição de um diploma suplementar ou 'Suplemento Europeu de Título"; "adotar um sistema facilmente comparável de dois níveis: Graduação e Pós-Graduação"; "aplicação generalizada do Sistema Europeu de Crédito (ECTS), que estabelece critérios para equivalência de créditos"; "promover a mobilidade"; "promover a cooperação entre os sistemas educativos europeus para assegurar a qualidade"; "promover a dimensão europeia na educação superior". $\mathrm{Na}$ avaliação de Dias Sobrinho (2009, p. 134) a "Declaração de Bolonha" representa "o registro formal de um importante processo que visa criar uma sólida convergência na educação superior europeia, a fim de que esta responda adequada e eficientemente aos problemas, oportunidades e desafios gestados pela globalização da economia". Transcorridos mais de quinze anos, é possível fazer um balanço sobre seu significado para a Europa e a repercussão que teve para outras regiões, inclusive no Brasil.

O presente artigo tem por objetivo, nos limites de um breve ensaio, analisar que confluências existem entre a expansão da educação superior brasileira e o Processo de Bolonha. Para tanto, iniciamos apresentando os números da expansão da Educação Superior no Brasil no recorte temporal 2000-2012; na sequência apresentamos os princípios do processo de Bolonha como sendo a resposta europeia aos desafios locais e globais da expansão e contestação do modelo tradicional de educação superior vigente na década de 1990; por fim, analisamos, a partir de algumas evidências, quais as relações existentes entre o processo de Bolonha e a expansão da Educação Superior no Brasil ocorrida no início do século XXI. 


\section{A expansão da educação superior no Brasil no período de 2000 a 2012}

O resumo técnico do censo de educação superior relativo ao ano 2012 aponta números expressivos em relação ao cenário atual da educação superior no Brasil. Segundo os números oficiais, as instituições de educação superior são majoritariamente privadas $(87,4 \%)$, o que demonstra um grande investimento do setor em relação ao público em todas as regiões do país, como se pode verificar na tabela abaixo:

Tabela 1: Número de instituições de educação superior, por categoria administrativa (pública e privada), segundo a região geográfica - Brasil - 2012

\begin{tabular}{l|r|r|r}
\hline \multirow{2}{*}{ Região geográfica } & \multicolumn{2}{|c|}{ Categoria administrativa } & \multicolumn{2}{|c}{ Total } \\
\cline { 2 - 4 } & Pública & Privada & 154 \\
\hline Região Norte & 28 & 126 & 444 \\
Região Nordeste & 65 & 379 & 1.173 \\
Região Sudeste & 143 & 1.030 & 236 \\
Região Centro-Oeste & 19 & 217 & 409 \\
Região Sul & 49 & 360 & \\
\hline
\end{tabular}

Fonte: INEP (2014).

A partir de tais dados, é possível perceber que a grande maioria das instituições está localizada na Região Sudeste. A superioridade de instituições é considerável na rede pública, porém os números são mais expressivos na rede privada 0 que pode ser explicado pelo contingente populacional e pela condição financeira da região. Os menores números de instituições, por sua vez, estão na Região Norte e Centro-Oeste, onde também é possível perceber a predominância das instituições privadas, porém em número menor que nas demais regiões do país. Tal diferença mostra que a iniciativa privada prefere as regiões do país que possuem atrativos que viabilizem seus investimentos, como contingente populacional, circulação de bens e serviços, infraestrutura e recursos humanos.

$\mathrm{Na}$ tabela que segue, é possível verificar, agora em nível nacional, o crescimento das instituições de educação superior segundo a categoria administrativa, o que confirma o interesse da iniciativa privada no negócio educação superior, corroborando a afirmação de Rossato (2011, p. 186) de que "com a perspectiva de que o mundo é um grande mercado, a educação passa a ser vista como uma moeda de troca, e um produto a ser disputado no vasto universo dos negócios". 
Tabela 2 : Evolução do número de instituições de educação superior, segundo a categoria administrativa, no período de 2000 a 2012

\begin{tabular}{l|r|r|r}
\hline \multirow{2}{*}{ Ano } & \multicolumn{2}{|c|}{ Categoria administrativa } & \multicolumn{2}{|c}{ Total } \\
\cline { 2 - 3 } & Pública & \multicolumn{1}{|c}{ Privada } & 1.118 \\
2000 & 176 & 1.004 & 1.391 \\
2001 & 183 & 1.208 & 2.270 \\
2006 & 248 & 2.022 & 2.416 \\
2012 & 304 & 2.112 & \\
\hline
\end{tabular}

Fonte: INEP $(2005,2012,2014)$.

Destacam-se nesses doze anos o nascimento de 1.298 instituições de educação superior, ficando evidente a hegemonia do número de instituições privadas que praticamente dobram o número de instituições, em relação às públicas que não conseguem atingir a mesma marca de crescimento. Diante de tais números torna-se evidente a afirmação de Dias Sobrinho (2009, p. 141) de que "a educação superior além de suas funções de democratização, está sendo um dos mercados mais atraentes e lucrativos, para as instituições e países”. A distribuição do número de matrículas é decorrente desse contexto, ou seja, a grande concentração de matrículas está localizada nas instituições privadas, conforme é possível observar na tabela a seguir:

Tabela 3: Evolução do número de matrículas da graduação, segundo a categoria administrativa

\begin{tabular}{l|r|r|r}
\hline \multirow{2}{*}{ Ano } & \multicolumn{2}{|c|}{ Categoria Administrativa } & \multirow{2}{*}{ Total } \\
\cline { 2 - 3 } & Pública & \multicolumn{1}{|c}{ Privada } \\
\hline 2000 & - & - & 2.694 .245 \\
2001 & 944.584 & 2.091 .529 & 3.036 .113 \\
2006 & 1.251 .365 & 3.632 .487 & 4.883 .852 \\
2012 & 1.879 .376 & 5.140 .312 & 7.037 .688 \\
\hline
\end{tabular}

Fonte: INEP (2005, 2012, 2014).

Verifica-se que a tendência histórica de as instituições de educação superior no Brasil estarem, na sua maioria, vinculadas ao setor privado se confirma. Os dados do Censo da Educação Superior 2012 mostram que o perfil predominante é de faculdades, as quais se caracterizam por atuar em um número reduzido de áreas, não ter autonomia para criar programas de ensino e cursos; são privadas e estão localizadas no interior do país (Inep, 2014, p. 78). Assim, é possível afirmar que a educação como espaço de negócios comandado pela iniciativa privada demonstra destreza e desenvoltura em satisfazer as tendências de mercado (ROSSATO, 2011, p. 186). 
Os números expressivos de matrículas e de instituições de educação superior não deixam dúvida de que vivemos, no período indicado, um fenômeno significativo em relação à expansão, porém tal crescimento reflete por um lado, a desestabilização do mundo do trabalho o que leva à busca crescente pelo diploma universitário como elemento importante na garantia da empregabilidade, e de outro, a lógica da economia globalizada, ou seja, o grande protagonista da expansão não são os investimentos públicos mas a abertura para o mundo do capital (ROSSATO, 2011, p. 186). Este, por sua vez, aproveita as novas oportunidades de negócio e as fatias do mercado principalmente no interior do país, onde se destaca a instalação de faculdades. Assim, as políticas de expansão da educação superior no Brasil seguem a tendência mundial em que os investimentos do Estado tendem sempre a diminuir e as Universidade públicas a passar por sérios problemas, abrindo um espaço que é rapidamente ocupado pelas instituições privadas (ZGAGA, 2011, p. 55). Tais fatos mostram que as políticas de expansão foram efetivas quando relacionadas às instituições que têm como foco principal o ensino, enquanto que as universidades responsáveis pelo ensino, pesquisa e extensão, permanecem em ritmo mais lento de crescimento como se pode observar abaixo:

Tabela 4: Evolução do número de instituições de educação superior, segundo a Organização Acadêmica

\begin{tabular}{r|r|r|r|r|r}
\hline \multirow{2}{*}{ Ano } & \multicolumn{4}{|c|}{ Organização acadêmica } & \multirow{2}{*}{ Total } \\
\cline { 2 - 6 } & Universidade & Centro Universitário & Faculdade & IF e CEFET & 1.637 \\
2002 & 162 & 77 & 1.398 & - & - \\
2006 & 178 & 119 & 1.973 & 3.270 \\
2009 & 186 & 127 & 1.966 & 35 & 2.314 \\
2012 & 193 & 139 & 2.044 & 40 & 2.416 \\
\hline
\end{tabular}

Fonte: INEP $(2005,2012,2014)$.

Apesar de o número de Universidades ser muito inferior ao de Faculdades, segundo os dados de 2012 , a maioria $(50,8 \%)$ das matrículas em cursos de graduação presencial está nas universidades, seguidas das faculdades (33,5\%), que são, prioritariamente, instituições privadas; além disso, os dados apontam que nas instituições privadas, a maioria dos alunos prevalece matriculada em cursos de graduação presencial no noturno $(73,2 \%)$, enquanto que na rede federal, cerca de $70 \%$ das matrículas estão concentradas em cursos presenciais no diurno; as instituições públicas estaduais têm mais da metade $(58,6 \%)$ de suas matrículas nos cursos presenciais no diurno e as públicas municipais têm a composição de suas matrículas por turno parecida com as privadas (Inep, 2014, p. 61). A concentração das matrículas nas Universidades revela que tais instituições, sejam públicas ou privadas, por serem de grande porte e com uma longa trajetória de ensino, pesquisa e extensão, 
desempenham um papel fundamental no cenário nacional. No entanto, ainda é discrepante o número de matrículas por turno, revelando que ainda as instituições privadas continuam sendo uma opção para aquele contingente de estudantes que precisa trabalhar durante o dia, enquanto que a federal é opção para aqueles que não precisam, necessariamente, trabalhar para se manterem estudando.

Tal cenário da educação superior brasileira aponta para a adequação à tendência mundial globalizadora: de um lado, os números expressivos apontam para a massificação da educação superior pela expansão do número de vagas e de matrículas; por outro, fica evidente a predominância do setor privado nesse processo, ao passo que o setor público cresce timidamente e passa a exercer a função de regulador e fiscalizador, como se pode observar na Lei 10.861, de 14 de abril de 2004, a qual institui o Sistema Nacional de Avaliação da Educação Superior/Sinaes. A partir de tal marco legal, todos os curso e instituições brasileiras estão submetidos às avaliações periódicas, orquestradas pelo Ministério da Educação.

Os números e aspectos destacados até aqui nos mostram quais são os rumos que a educação superior no país tem tomado, sob a lógica da globalização mundial. Desse modo, a preocupação com a internacionalização, a lógica do mercado de trabalho sob a égide do neoliberalismo, os processos regulatórios e de avaliação, a mobilidade estudantil e o espaço no mundo do conhecimento, influenciam decisivamente os rumos das políticas públicas. Fazer parte desse cenário mundial implica em rever muitos aspectos do modo como tradicionalmente se organizou a educação superior brasileira, assim como aconteceu com a Europa por meio do Processo de Bolonha, o qual servira de base para muitas das decisões tomadas no Brasil.

O Processo de Bolonha surge como uma proposta europeia para a resolução de seus próprios problemas, levando em consideração o contexto de expansão e de contestação do modelo tradicional vigente na década de 1990. Um movimento que surge para dar conta de um cenário específico, ainda que globalizado, como o Processo de Bolonha, teria influência nas políticas educacionais brasileiras para a educação superior diante do cenário acima descrito? É o que procuraremos mostrar a seguir.

\section{0 contexto e os princípios do Processo de Bolonha: a resposta europeia aos desafios locais e globais}

A iniciativa para a consolidação do Processo de Bolonha se justifica pela contribuição que o desenvolvimento educacional poderia trazer para a comunidade europeia, em seu sentido mais amplo, e para os cidadãos em sentido restrito e concreto, diante de um novo cenário econômico mundial, no qual o espaço europeu 
precisava marcar posição. Tal iniciativa estaria em consonância com a crescente conscientização política e acadêmica mundial que reiterava a necessidade e a importância das dimensões intelectual, cultural, social, científica e tecnológica para o desenvolvimento das nações. Nessa direção, o documento registra que a busca pela qualificação dos processos educacionais e de produção do conhecimento é condição para o desenvolvimento social e humano, sendo capaz de promover espaços e oportunidades que possibilitarão aos seus cidadãos o desenvolvimento de "aptidões necessárias para enfrentar os desafios do novo milênio" aliando "a consciência de partilha dos valores" e a "pertença a um espaço social e cultural comum” (BOLOGNA DECLARATION, 1999). Percebe-se, assim, que o Processo de Bolonha está amparado no modelo global de desenvolvimento, calcado na inovação e em padrões de competitividade maleáveis e flexíveis. Inserir-se nesse cenário implica em reconhecer que a lógica da diferenciação, pela capacidade de criação e de força competitiva, está aliada à rapidez das transformações e a novas demandas de um mundo que diminui as fronteiras entre o local e o global. Assim, aponta para a necessidade do trabalho em rede e da cooperação para potencialização da produtividade e competitividade, o qual não seria possível pelo trabalho isolado. Diante do contexto de alta produtividade e rapidez das mudanças, se torna insuficiente preparar somente para o trabalho, já que, como afirma Bolívar, "la fuerza de trabajo de la Unión Europea debe ser um factor de innovación, productividad y competitividade" (2011, p. 110), tornando a aquisição de competências mais importante que a simples qualificação para o trabalho. Segundo o autor, essa máxima é uma das variáveis que, se tomada de modo apressado e acrítico, contribui para a incorporação da lógica do mundo empresarial na educação superior, tomando-o como modelo de formação, reflexo das "políticas neoliberales que subordinan la educaicón a las demandas del mercado y a la gestión de los recursos humanos" (BOLÍVAR, 2011, p. 110), do que para a formação como processo que contribui para a formação humana, tendo como um de seus aspectos a qualificação profissional.

Fica claro no documento a premissa de que não se constrói uma Europa do Conhecimento competitiva, atraente e valorizada sem um processo educativo voltado para o enfrentamento das demandas oriundas de um novo contexto econômico global, interdependente e interconectado. Para isso, era preciso contar com a Universidade europeia, já que as bases da economia assentadas no desenvolvimento tecnológico implicavam em rever os modelos de organização das instituições produtoras de conhecimento e formadoras de profissionais. Para isso eram necessárias algumas ações que perpassavam os seguintes aspectos: (i) a preocupação com a formação para a empregabilidade, já que o emprego é fundamental para o desenvolvimento econômico e social; (ii) a equiparação e equivalência dos graus acadêmicos, 
a fim de tornar o Sistema Europeu de Educação Superior atrativo, seja pela sua agilidade burocrática ou pela qualidade e diferenciação dos processos formativos; (iii) eficiência e rapidez do tempo de formação, sendo, para isso, necessária a redução para três anos da formação na graduação, integrando os egressos ao mercado de trabalho mais rapidamente e aligeirando o acesso ao nível da pós-graduação; (iv) promover a adaptabilidade dos currículos e a valorização das aprendizagens construídas em diversos espaços formativos, de modo a aproveitar a potencialidade dos espaços de formação alternativos que contribuem para a formação profissional de seus cidadãos e da captação de novas demandas e soluções para os problemas emergentes, ampliando o repertório de conhecimentos para além da 'academia'. No entanto, há a preocupação com a validação desses conhecimentos, ou seja, com o reconhecimento desses como social e academicamente válidos, por isso, validados pelas instituições formais, evitando uma espécie 'vale tudo' e valorizando as experiências formativas; (v) a mobilidade de estudantes, professores e demais profissionais da educação, de modo a potencializar o intercâmbio de conhecimentos e práticas pedagógicas e profissionais. Evidencia-se a iniciativa de tornar mais efetiva e orgânica a cooperação entre as instituições de ensino superior, de modo a potencializar a produção do conhecimento; (vi) a cooperação para a busca pela qualidade, já que é ela que elevaria os graus de notoriedade e interesse mundial pela Europa. Com o desenvolvimento de critérios e metodologias adequadas seria possível elevar os níveis de qualidade da formação e de produção de conhecimento, consolidando a coerência, a atratividade e a competitividade do Sistema Europeu de Educação Superior; (vii) a grande reforma em busca da qualidade e da competitividade teria que contar com reorganização das instituições a fim de dar conta das novas demandas, desse modo, implicando no realinhamento de suas propostas pedagógicas e curriculares, assim como de parceiras interinstitucionais, circulação de pessoas e propostas de integração entre formação, mercado de trabalho e pesquisa.

Nesse sentido, é possível afirmar que o Processo de Bolonha consiste num conjunto de propostas europeias para dar conta de seus próprios problemas, conforme afirma Zgaga (2011, p. 64) "o Processo de Bolonha é algo que não se experimentou antes. É uma resposta Europeia específica em resposta aos seus problemas históricos europeus, mas é também uma resposta ao contexto global". Para isso, aponta para os ajustes que precisam ser feitos nas instituições de educação superior, a fim de garantir a produção de novos conhecimentos de modo cooperativo, uma vez que sozinhas diante das novas conjunturas de desenvolvimento tecnológico seria inviável. Assim, a abertura de novas possibilidades de intercâmbio de conhecimento e pessoas, de modo a promover a formação para o trabalho, novas oportunidades de emprego e pesquisa cooperativa, torna-se um condicionante de primeira ordem. 
Fica claro que para dar conta dos seus problemas econômicos, políticos e epistemológicos, que são também problemas globais, a Europa vê as instituições de educação superior como uma engrenagem central, já que são as principais instâncias formadoras de profissionais e produtoras de conhecimento. Entretanto, há o perigo eminente da lógica acadêmica sucumbir diante da lógica econômica mercadológica, como aponta Bolívar (2011). As instituições de educação superior, tanto na Europa como nos demais continentes, não passam imunes por essa pressão. A seguir, buscaremos apontar qual a influência do processo de Bolonha nas políticas de expansão do ensino superior no Brasil.

\section{0 contexto de expansão da educação superior brasileira no período de 2000 a 2012 e sua relação com o Processo de Bolonha: a resposta brasileira aos desafios locais e globais}

Seria ingênuo acreditar que todas as mudanças ocorridas nas últimas duas décadas na condução das políticas públicas para a Educação Superior no Brasil são desdobramentos do Processo de Bolonha; de mesma forma seria simplista dizer que todas as proposições legislativas que regulamentam a Educação Superior se devem aos ditames dos organismos internacionais (OCDE, Bird, BM, FMI, Unesco etc.) que, com mão de ferro, orquestram o funcionamento do Mercado Educacional; não seria sensato defender a posição intransigente de que todas as mudanças ocorridas no âmbito da Educação Superior foram maquiavelicamente planejadas por organismos internacionais, estão previstos no Processo de Bolonha e que, portanto, não há espaços de autonomia para o planejamento das políticas públicas para a Educação Superior Brasileira. De outra parte, não podemos negar que há fortes influências dos organismos internacionais e do Processo de Bolonha nos processos de condução e decisão da forma como tem se desdobrado a Educação Superior Brasileira. Neste último tópico do artigo, pretendemos analisar, a partir de alguns exemplos, de que forma os indicativos do Processo de Bolonha se fazem sentir na resposta brasileira dada aos desafios locais e globais da expansão da educação superior.

Tomando por base os números da expansão da educação superior brasileira, rapidamente apresentados na primeira parte do presente artigo, salta aos olhos a vertiginosa expansão privada tanto em termos de instituições quanto do número de matrículas. Tomando por base os números do período analisado (2000 a 2012), vemos que enquanto tivemos a criação de 128 instituições públicas, foram criadas 1.298 instituições privadas (conforme Tabela 2). A evolução do número de matriculas também reforça essa constatação da expansão pelo caminho da privatização. 
Conforme Tabela 3, enquanto que em 2012 temos um total de 1.879.376 matrículas em instituições públicas, no setor privado temos um total de 7.037.688 matrículas, ou seja, há uma diferença de 5.158.312 entre a soma das matrículas efetivadas em instituições públicas e as efetivadas em instituições privadas. Essa primeira constatação vem reforçar a tese de Suely Ferreira (2009) de que houve no século $\mathrm{XX}$ três ondas reformistas na América Latina: a primeira delas aconteceu no início do século e se apresentou como uma resposta às demandas das classes médias, da industrialização e da expansão das universidades públicas e teve como resultado a difusão do modelo universitário público, gratuito e laico (no Brasil tal modelo teve pouco êxito em função do nascimento tardio da Universidade Brasileira); a segunda reforma iniciou-se nos inícios dos anos de 1970, no contexto das ditaduras militares, no cenário da crise do petróleo, da crise fiscal, da diminuição dos preços das matérias-primas que acabou gerando dificuldades para os Estados continuarem a expansão do financiamento público para as Universidades (podemos dizer que é nesta segunda onda de reforma que ocorre a expansão desordenada das IES privadas e a diferenciação expressiva de instituições); a terceira reforma vem marcada pelo processo de internacionalização da educação superior, possibilitada pela presença forte das novas tecnologias da informação, das demandas das populações excluídas deste nível de ensino, da educação ao longo da vida, da mercantilização do conhecimento e da renovação permanente dos saberes. No dizer de Ferreira (2009, p. 44), "a internacionalização vem promovendo a mobilidade estudantil, o estabelecimento de standarts internacionais de qualidade, da importância da relevância local e global, da educação transfronteiriça e das modalidades de educação em rede, da educação virtual”.

Uma observação panorâmica dessas três reformas apontadas por Ferreira (2009) nos leva a identificar que a expansão da educação superior em curso no Brasil, nas últimas duas décadas, situa-se entre as segunda e terceira ondas reformistas. Temos, portanto, um misto entre a expansão das IES privadas, a diferenciação das instituições e uma tentativa de internacionalização da educação superior. No que tange à terceira onda reformista, tem razão Catani e Gilioli quando dizem que ela "possui notável sinergia com os parâmetros que regem a implementação do Espaço Europeu de Educação Superior” (2011, p. 219).

Talvez seja forçoso dizer que está havendo a incorporação e a aplicação dos princípios do Processo de Bolonha na expansão da Educação Superior no Brasil. Sobre esse aspecto, concordamos com Dias Sobrinho quando diz que mesmo diante dos resultados já alcançados "a ponto de ter-se tornado uma ampla referência internacional, não se pode dizer que esse processo já esteja fazendo parte da vida cotidiana das instituições educativas e já tenha recebido ampla adesão da comuni- 
dade acadêmica e científica" (2009, p. 143). Há grandes distâncias entre a proposição de uma reforma e a adesão incontestável dos seus princípios e práticas. Seria equivocado afirmar que as políticas educacionais desenvolvidas recentemente no Brasil seguem perceptivelmente a cartilha do Processo de Bolonha. No entanto, há certas experiências localizadas que poderiam ser ilustrativas do quanto os indicativos do Processo de Bolonha se fazem presentes na forma como tem se desenvolvido a expansão da Educação Superior no Brasil. Em seu texto A Universidade Brasileira face ao Processo de Bolonha, o pesquisador Ricardo Rossato (2011) analisa traços fundamentais do processo de Bolonha a partir da criação da Universidade Federal do ABC (UFABC) e da forma como foi projetada a implantação do Reuni ${ }^{1}$ na Universidade Federal da Bahia (UFBA).

O estudo de Rossato (2011) sobre a criação da Universidade Federal do ABC, ressalta alguns elementos do Projeto Pedagógico da referida instituição, datado de fevereiro de 2006, o qual possui interfaces com o Processo de Bolonha. O documento, por exemplo, "reafirma a necessidade de flexibilização da universidade face à reorganização do mundo do trabalho criando novas exigências de formação" (2011, p. 196). O projeto pedagógico também destaca como sendo um aspecto fundamental "a adequação da nova universidade ao mercado de trabalho" da seguinte maneira: "a Universidade tem como expectativa promover cursos que possam proporcionar aos estudantes recursos pedagógicos para a aquisição das ferramentas necessárias a uma atuação ágil e flexível no mercado de trabalho, tornando-os aptos a se adaptarem a diversas atividades do trabalho" (UFABC, 2006, p. 9).

A estrutura curricular da UFABC (2006, p. 12) também evidencia traços importantes dos princípios do Processo de Bolonha, quando essa é dividida em duas etapas: a primeira diz respeito aos "ciclos iniciais de três anos, conduzindo ao $\mathrm{Ba}$ charelado em Ciência e Tecnologia"; a segunda diz respeito ao "Ciclo complementar de um ano para licenciatura ou bacharelado específico (Física, Química, Matemática, Computação, Biologia) ou Ciclo profissional de dois anos para Engenharia". Conforme observa acertadamente Rossato (2011, p. 197), “o ciclo inicial assegura o grau de Bacharel em Ciência e Tecnologia pode ter um caráter terminal”, ou seja, ao final do primeiro ciclo "o egresso poderá ir diretamente para o mercado de trabalho".

No que se refere à implantação do Reuni na Universidade Federal da Bahia (UFBA), Rossato destaca o fato de que já em 2007 a referida instituição lançou um documento preliminar do projeto para a implantação do referido programa, "chamando a atenção para o processo de Bolonha como um exemplo eloquente de uma nova concepção acadêmica, face às demandas da sociedade do conhecimento" (2011, p. 199). Em seu Projeto Pedagógico dos Bacharelados Interdisciplinares, a UFBA propõe fazer um ajuste da estrutura acadêmica possibilitando "uma transforma- 
ção radical da arquitetura acadêmica da universidade pública brasileira, visando superar desafios e corrigir os defeitos” (2008, p. 4). A principal alteração proposta na estrutura curricular da universidade implica na implantação do regime de três ciclos de educação superior: 1) Bacharelado Interdisciplinar (Primeiro Ciclo) - propiciando formação universitária geral, como pré-requisito para progressão dos ciclos seguintes; 2) Formação Profissional em Licenciatura ou Carreiras Específicas (Segundo Ciclo); 3) Formação Acadêmica Científica, Artística e Profissional em nível de pós-graduação (Terceiro Ciclo). Conforme ressalta Rossato, no conjunto das mudanças propostas pelo projeto de implantação do Reuni da UFBA, "destacamos a mobilidade intra e interinstitucional, regime de ciclos de formação, estrutura curricular: interdisciplinar, modular, flexível e progressiva" (2011, p. 202). Se revisarmos cuidadosamente as ações proposta pelo Processo de Bolonha, sintetizados no terceiro tópico do presente artigo, claramente veremos algumas interfaces com a proposta de implantação do Reuni da UFBA.

\section{Considerações finais}

Os números apresentados na primeira parte do artigo revelam não apenas a expansão das instituições e das matrículas na Educação Superior no Brasil no período analisado, mas principalmente o perfil dessa expansão, que revela tanto a desestabilização do mundo do trabalho quanto a lógica da economia globalizada. Nesse sentido, a expansão da Educação Superior no Brasil reflete a tendência da lógica da globalização mundial. Com isso não estamos inferindo que a expansão é um reflexo direto do Processo de Bolonha. Conforme ressaltamos no artigo, seria forçoso dizer que houve uma aplicação direta dos princípios da Declaração de Bolonha na forma como se desenvolveram as políticas de expansão e regulação da Educação Superior no Brasil. De outra parte, há fortes evidências em experiências localizadas de indicativos dos princípios e ações da Declaração de Bolonha na forma como foram projetadas certas políticas públicas de Expansão da Educação Superior no Brasil.

Concordamos com Dias Sobrinho quando afirma que há "resistências, desafios e tensões na implementação do Processo de Bolonha". Transcorridos mais de 15 anos de sua assinatura, “o processo ainda provoca dúvidas e inquietações" (2009, p. 143-144). Uma avaliação preliminar indica que há acertos e críticas de diversos teores: critica-se por ter sido "uma reforma aplicada de cima para baixo, basicamente de caráter legal, sem que a comunidade universitária tivesse oportunidade de participar amplamente de suas discussões"; há preocupação no que diz respeito à descaracterização das "funções essenciais da educação superior" e por isso "mui- 
tos da comunidade acadêmica e científica temem que a universidade perca suas perspectivas a longo prazo e se afaste de suas referências sociais", quando o mercado de trabalho passa a determinar a formação universitária; tanto a Declaração de Bolonha quanto as demais declarações explicitam "boas intenções" e não prevalece "o sentido explicitamente comercial”, pois "o propósito central anunciado no texto é consolidar amplos processos interativos de incorporação de todas as dimensões científicas, pedagógicas, culturais e globais da educação superior”; a intenção da Declaração poderia ser "um poderoso instrumento para a realização do sonho de construção de uma Europa do conhecimento, unida, solidária, moderna, competente e competitiva" (DIAS SOBRINHO, 2009, p. 144).

No entanto, há um enorme abismo entre o que se anunciou em termos de intenções e a forma como se efetivam na prática. Não há dúvida que muitas intenções programáticas de cooperação se transformam rapidamente em perigosos mecanismos de competição, principalmente quando são alimentados pela lógica do mercado. Como nos alerta Dias Sobrinho, "muitas vezes é difícil distinguir entre cooperação e competição, até onde vai uma e a outra começa” (2009, p. 144). Assim, "os intercâmbios muito pouco têm dos sentidos da tradicional solidariedade universitária ou de uma cooperação visando somente o desenvolvimento da ciência universal e desinteressada”. De forma analógica, podemos inferir que a expansão da Educação Superior brasileira também tem importantes e contraditórias divergências entre as intenções programáticas e a forma como tal expansão se efetivou e está se concretizando no Brasil.

\title{
Confluences of expansion of brazilian higher education in the 2000-2012 period and the Bologna process
}

Abstract

\begin{abstract}
This article deals with the possible relationship between the expansion of Brazilian Higher Education and the Bologna Process. In this short essay, our goal is to analyze confluences that exist between the expansionist policies of Higher Education, which has recently occurred in Brazil, and the principles expressed in the Declaration of Bologna. We started presenting the issues of expansion of Higher Education in Brazil from 2000 to 2012. Following up, we look at the principles of the Bologna Process as the European response to local and global challenges of expansion and confrontation to the traditional model of current Higher Education in the 1990s. Finally, considering some evidence, we analyze which relationships exist between the Bologna Process and the expansion of Higher Education in Brazil that occurred in the early $21^{\text {st }}$ century.
\end{abstract}

Keywords: Expansion of Higher Education. Educational Policy. Bologna Process. 


\section{Notas}

1 O Programa de reestruturação e Expansão das Universidades Federais - Reuni, foi instituído em 2007 pelo governo federal, por meio do Decreto 6.096/2007. Tal programa teve por objetivo ampliar o acesso e a permanência na educação superior por meio da expansão física, acadêmica e pedagógica da rede federal de educação superior. Em seus projetos, as universidades tiveram de apresentar também propostas de revisão de sua estrutura acadêmico-curricular por meio da reorganização dos cursos de graduação, implantação de regimes curriculares e sistemas de títulos que possibilitem a construção de itinerários formativos diferenciados, além da promoção de mobilidade estudantil. Não há referência direta ao processo de Bolonha. Porém, no ano de 2010, o Ministério da Educação (MEC) publicou o documento intitulado Referenciais Orientadores para os Bacharelados Interdisciplinares e Similares, propondo a implantação do regime de ciclos na educação superior brasileira sob a premissa de ampliar as opções de formação no interior das instituições universitárias (BRASIL, 2010). No referido documento, admite-se que as referências para a adoção do regime de ciclos e do Bacharelado Interdisciplinar nas universidades brasileiras são inspiradas "na organização da formação superior proposta por Anísio Teixeira para a concepção da Universidade de Brasília, no início da década de 1960, no Processo de Bolonha e nos colleges estadunidenses" (BRASIL, 2010). Dessa forma, estabelece-se, oficialmente, a influência do processo europeu na reconfiguração da universidade brasileira.

\section{Referências}

BOLÍVAR, A. El enfoque por competecias en educación general u educación superior: entre la inclusión social y el mercado laboral. In: PEREIRA, E.M.A; ALMEIDA, M.L.P. (Org.). Reforma Universitária e a construção do espaço europeu de educação superior: análise de uma década do Processo de Bolonha. Campinas/SP: Mercado de Letras, 2011. p. 109-156.

BOLOGNA DECLARATION. Site oficial. 1999. Disponível em: <http://www.ond.vlaanderen.be/ hogeronderwijs/bologna/documents/MDC/BOLOGNA_DECLARATION1.pdf>. Acesso em: 30 set. 2015 .

CATANI, A. M.; GILIOLI, R. S. P. O processo de Bolonha na produção acadêmica brasileira: incursões preliminares. In: PEREIRA, E.M.A; ALMEIDA, M.L.P. (Org.). Reforma Universitária e a construção do espaço europeu de educação superior: análise de uma década do Processo de Bolonha. Campinas/SP: Mercado de Letras, 2011. p. 207-224.

BRASIL. Referenciais Orientadores para os Bacharelados Interdisciplinares e Similares. Brasília: MEC. 2010.

DIAS SOBRINHO, J. O Processo de Bolonha. In: PEREIRA, E. M. A; ALMEIDA, M. L. P. (Org.). Universidade contemporânea: políticas do processo de Bolonha. Campinas-SP: Mercado de Letras, 2009. p. 131-152.

FERREIRA, S. A universidade do século XXI: concepções, finalidades e contradições. Tese (Doutorado em Educação) — Universidade Federal de Goiás, Goiás, 2009.

INSTITUTO NACIONAL DE ESTUDOS E PESQUISAS EDUCACIONAIS ANÍSIO TEIXEIRA/ INEP. Censo da educação superior 2012: resumo técnico. Brasília: Inep, 2014. Disponível em: <http://download.inep.gov.br/download/superior/censo/2012/resumo_tecnico_censo_educacao_ superior_2012.pdf>. Acesso em: 30 set. 2015.

INSTITUTO NACIONAL DE ESTUDOS E PESQUISAS EDUCACIONAIS ANÍSIO TEIXEIRA/ INEP. Censo da educação superior 2010: resumo técnico. Brasília: Inep, 2012. Disponível em: <http://download.inep.gov.br/download/superior/censo/2010/resumo_tecnico_censo_educacao_ superior_2010.pdf>. Acesso em: 30 set. 2015. 
INSTITUTO NACIONAL DE ESTUDOS E PESQUISAS EDUCACIONAIS ANÍSIO TEIXEIRA/INEP. Censo da educação superior 2004: resumo técnico. Brasília: Inep, 2005. Disponível em: <http://download.inep.gov.br/download/superior/2004/censosuperior/Resumo_tecnico-Censo_2004.pdf>. Acesso em: 30 set. 2015.

ROSSATO, R. A universidade brasileira face ao Processo de Bolonha. In: PEREIRA, E.M.A; ALMEIDA, M.L.P. (Org.). Reforma Universitária e a construção do espaço europeu de educação superior: análise de uma década do Processo de Bolonha. Campinas/SP: Mercado de Letras, 2011. pp. 181-205.

UFABC. Projeto Pedagógico. São Bernardo: UFABC, 2006.

UFBA. Projeto pedagógico dos Bacharelados Interdisciplinares. Salvador: UFBA, 2008.

ZGAGA, P. O Processo de Bolonha e seu papel nos países em transição. In: PEREIRA, E. M. A; ALMEIDA, M. L. P. (Org.). Reforma Universitária e a construção do espaço europeu de educação superior: análise de uma década do Processo de Bolonha. Campinas/SP: Mercado de Letras, 2011. p. 39-66. 